\title{
Tuberculosis among Patients Admitted to the Department of Medicine of a Tertiary Care Center in Nepal: A Descriptive Cross-sectional Study
}

\author{
Suman Thapa, ${ }^{1}$ Anupam Bista, ${ }^{1}$ Prashant Subedi, ${ }^{2}$ Aaradhana Adhikari, ${ }^{2}$ Sunil Pokharel ${ }^{2}$ \\ 'Department of Medicine, Patan Hospital, Patan Academy of Health Sciences, Lalitpur Nepal, ${ }^{2}$ Center for Tropical \\ Medicine and Global Health, Nuffield Department of Clinical Medicine, University of Oxford, Oxford, United \\ Kingdom.
}

\section{ABSTRACT}

Introduction: Tuberculosis has high burden in developing countries like Nepal. This study aims to determine the prevalence of tuberculosis among patients admitted in the department of medicine of a tertiary hospital.

Methods: A descriptive cross-sectional study of all the patients admitted to the tertiary care

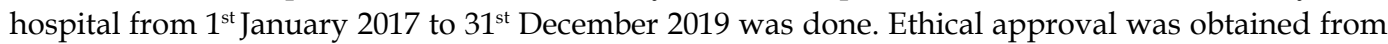
Institutional Review Committee (Ref: drs2006181387). Convenience sampling method was used. A descriptive analysis of demographic, clinical and laboratory profile of patients was made using Microsoft Excel version 2016. Point estimate at 95\% Confidence Interval was calculated along with frequency and proportion for binary data.

Results: Among 6829 patients admitted to the department of medicine, 209 (3.06\%) (2.65-3.47 at $95 \% \mathrm{Cl})$ patients were diagnosed with tuberculosis. Among them, 147 (70.33\%) were males and the mean age was 49.77 years. Pulmonary and extra-pulmonary tuberculosis were present in 153 (73.20\%) and $56(26.79 \%)$ patients, respectively. Bacteriological confirmation was limited to 107 (70\%) of pulmonary tuberculosis and $3(5 \%)$ of extrapulmonary tuberculosis. Fever was the commonest presentation in $166(79.42 \%)$ followed by cough in $164(78.46 \%)$, anorexia in 108 (51.67\%), weight loss $104(49.76 \%)$, and others.

Conclusions: The study showed that the prevalence of tuberculosis among admitted patients was higher than national prevalence.

Keywords: clinical profile; risk factors; tuberculosis.

\section{INTRODUCTION}

Tuberculosis is one of the commonest causes of morbidity and mortality worldwide.1,2 Evolving resistance to anti-tubercular drugs is a huge therapeutic challenge. ${ }^{3}$ In Nepal, around 69,000 people develop new active infections every year. ${ }^{4}$ Human immunodeficiency Viruses (HIV) co-infection, smoking and diabetes are significantly associated with tuberculosis infection and attributable deaths. ${ }^{5-7}$ Tuberculosis commonly presents with cough, fever, hemoptysis, anorexia and unintentional weight loss. ${ }^{5}$ Presentation varies depending upon infection site and other patient factors. ${ }^{8}$ A non-specific presentation, limited utility of culture, suboptimal sensitivity of acid fast bacilli (AFB) stain ${ }^{9}$ and unavailability of test like Xpert Mycobacterium tuberculosis (MTB)/rifampicin (RIF) at the point-of-care ${ }^{12,13}$ test make diagnosis a challenge.

Attempts to understand tuberculosis from the clinical and laboratory perspective in Nepal have largely been

Correspondence: Dr. Suman Thapa, Department of Medicine, Patan Academy of Health Sciences, Lalitpur, Nepal. Email: sumanthapa971@gmail.com, Phone: +9779851114860. 
Thapa et al. Tuberculosis among Patients Admitted to the Department of Medicine of a Tertiary Care Center in Nepal: A Descriptive...

focused on outpatients. ${ }^{10}$ Hospitalized patients are characterized differently and need special attention for early diagnosis and management. ${ }^{11}$

This study aims to determine the prevalence of tuberculosis among patients admitted in the department of medicine of a tertiary hospital.

\section{METHODS}

A descriptive cross-sectional study of patients admitted to the Department of Medicine of Patan Hospital from $1^{\text {st }}$ January 2017 to $31^{\text {st }}$ December 2019 was done. Ethical approval was obtained from Institutional Review Committee-Patan Academy of Health Sciences (Ref: drs2006181387) before the start of data collection. Convenience sampling was done and the sample size was calculated as,

$\mathrm{n}=\mathrm{Z}^{2} \times \mathrm{p} \times(1-\mathrm{p}) / \mathrm{e}^{2}$

$=(1.96)^{2} \times(0.5) \times(1-0.5) /(0.02)^{2}$

$=2401$

Where,

$\mathrm{n}=$ minimum required sample size

$\mathrm{Z}=1.96$ at $95 \%$ Confidence Interval (CI)

$\mathrm{p}=$ prevalence taken as $50 \%$ for maximum sample size $q=1-p$

$\mathrm{e}=$ margin of error, $2 \%$

As convenience sampling technique was used, the sample size was doubled to 4802 . Adding $10 \%$ for missing data, the sample size of 5282 was reached. But we collected data from 6829 patients.

All adult patient (15 years of age and above) admitted in medical ward, geriatric ward, step down, medical intensive care unit and private wards under Medicine Department of Patan hospital with diagnosis of tuberculosis (both pulmonary and extra pulmonary) from 1st January 2017 to 31st December 2019 were included in the study. A total of 209 hospital records of patients with tuberculosis were identified and analyzed.

We used the Centers for Disease Control and Prevention (CDC) definitions for smoking. ${ }^{12}$ Those patients who had never smoked or who had smoked less than 100 cigarettes in their lifetimes were defined as never smokers. Those patients who had smoked at least 100 cigarettes in their lifetimes but had quit smoking at time of interview were former smokers. Others who smoked currently at the time of interview and had smoked more than 100 cigarettes in lifetime were current smoker. The amount of smoking was expressed as pack year which was calculated by multiplying the number of packs of cigarettes smoked per day by the number of years the person had smoked.
A known case of HIV as per previous report or patients' self-declaration was considered as positive for HIV. For patients with unknown HIV status, case file and investigation were reviewed and were grouped as positive or negative based on available information. Those patients whose HIV reports were not available were grouped as status unknown.

A diagnosis of patients status for diabetes was established based on patients history, self-declaration, or report as available in case files. Blood investigation criteria for diagnosis of diabetes included fasting plasma glucose of more than $125 \mathrm{mg} / \mathrm{dl}$, two-hour postprandial plasma glucose level more than $199 \mathrm{mg} /$ $\mathrm{dl}$ or glycated hemoglobin $(\mathrm{HbA} 1 \mathrm{C})$ more than $6.4 \% .^{13}$

Anemia was said to be present when hemoglobin level was below $12 \mathrm{gm} / \mathrm{dl}$ in female and $13 \mathrm{gm} / \mathrm{dl}$ in male. Anemia was further classified into mild, moderate and severe using the blood hemoglobin level cut-offs of $11 \mathrm{gm} / \mathrm{dl}$ and above, 8-10.9 gm/dl and below $8 \mathrm{gm} / \mathrm{dl}$ respectively. ${ }^{14}$

Hospital records of patients admitted with a diagnosis of tuberculosis were identified from the patient record section of the hospital, which archives the patient records following International Statistical Classification of Diseases and Related Health Problems Version $10 .{ }^{15}$ Individual patient files were accessed and reviewed for relevant data by the study investigators. A standard performa was used to retrieve and record the demographic, clinical and laboratory data of the patients. The proforma was anonymized generating a unique patient identifier for each patient.

Data was collected in standard paper proforma and later entered into a secure computer system using Microsoft Excel Version 2016. A descriptive analysis of all obtained data was done and point estimate at $95 \%$ $\mathrm{Cl}$ was calculated along with frequency and proportion for binary data.

\section{RESULTS}

Among 6829 patients admitted in department of medicine of Patan Hospital, 209 (3.06\%) (2.65-3.47 at $95 \% \mathrm{Cl}$ ) were diagnosed with tuberculosis. Out of the 209 patients diagnosed with tuberculosis, 147 (70.33\%) were males and $62(29.67 \%)$ were females, and the mean age of participants was 49.77 years. The mean length of hospital stay among these patients was 6.9 days.

$153(73.20 \%)$ patients had pulmonary tuberculosis, with involvement of at least one extrapulmonary sites in $29(18.95 \%)$ patients and more than one in $6(3.92 \%)$ patients. $56(26.79 \%)$ patients had extrapulmonary tuberculosis with involvement of various organs 
Thapa et al. Tuberculosis among Patients Admitted to the Department of Medicine of a Tertiary Care Center in Nepal: A Descriptive...

(Table 1, Figure 1).

\begin{tabular}{|c|c|}
\hline \multicolumn{2}{|c|}{$\begin{array}{l}\text { Table 1. Pulmonary Tuberculosis with extrapulmonar } \\
\text { dissemination. }\end{array}$} \\
\hline $\begin{array}{l}\text { Extrapulmonary dissemination in patients } \\
\text { with pulmonary tuberculosis }\end{array}$ & n (\%) \\
\hline Pleural & $10(6.53)$ \\
\hline Central Nervous System & $6(3.92)$ \\
\hline Abdominal & $11(7.18)$ \\
\hline Potts's spine & $2(1.30)$ \\
\hline Lymph node & $5(3.26)$ \\
\hline Osteomyelitis & $1(0.65)$ \\
\hline Total & $35(100)$ \\
\hline
\end{tabular}

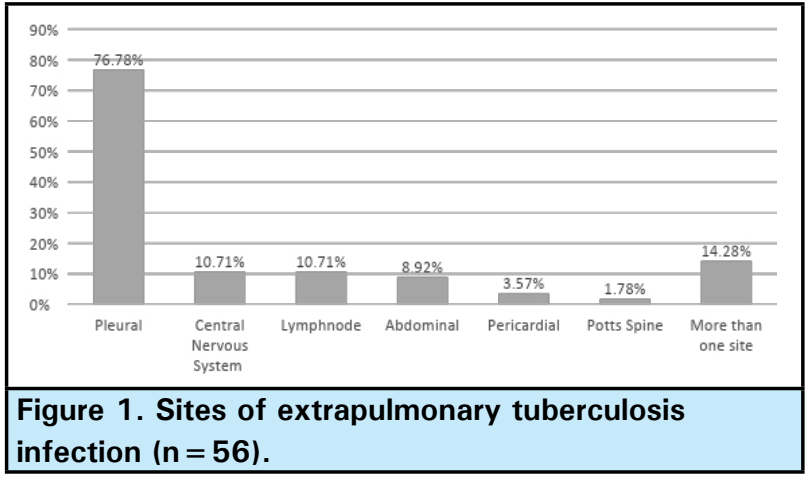

Smoking, diabetes, and HIV co-infection was present in $90(43.06 \%), 25(11.96 \%)$ and $3(1.43 \%)$ patients, respectively. $64(71.11 \%)$ of the smokers were current smokers. The mean pack years among 87 smokers was 15.21. Mean $\mathrm{HbA} 1 \mathrm{c}$ among 23 diabetic patient was $8.65 \%$.

Fever was the commonest presentation in 166 (79.42\%) followed by cough in 164 (78.46\%), anorexia in 108 (51.67\%), weight loss 104 (49.76\%). Other symptoms were breathlessness in $99(47.36 \%)$, chest pain in 48 (22.96\%), haemoptysis in 27 (12.91\%) patients (Figure 2).

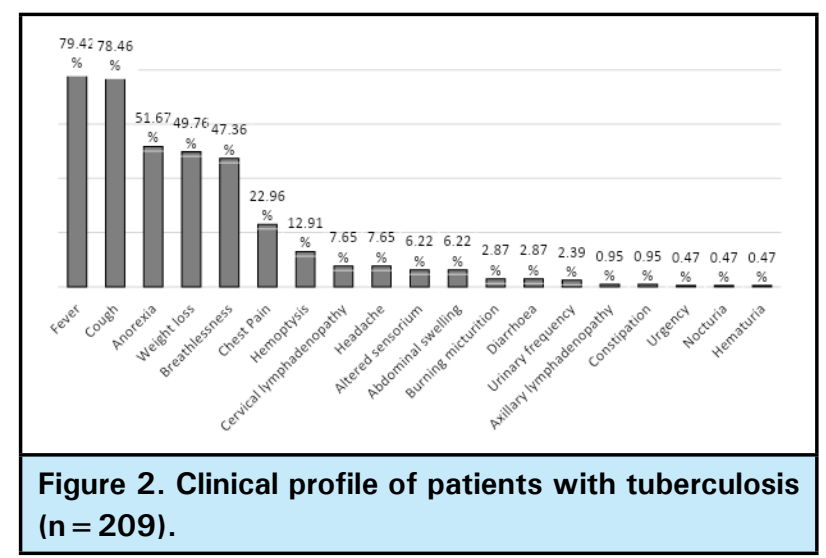

Laboratory investigations showed the abnormal leukocyte counts in 68 (32.53\%) patients, raised neutrophil lymphocyte ratio (NLR) in 167 (79.91\%) patients, raised erythrocyte sedimentation rate (ESR) in 119 (92.25\%) patients and anemia in 177 (84.69\%) patients (Table 2).

\begin{tabular}{|lc|}
\hline $\begin{array}{l}\text { Table 2. Laboratory profile of } \\
\text { tuberculosis. }\end{array}$ & patients with \\
\hline Laboratory parameters & $\mathrm{n}(\%)$ \\
Abnormal WBC count & $68(32.5)$ \\
Leukopenia & $4(1.91)$ \\
Leukocytosis & $64(30.62)$ \\
Increased NLR ratio $\geq 2.9$ & $167(79.9)$ \\
Raised ESR & $119(92.25)$ \\
$20-99 \mathrm{~mm} / \mathrm{hr}$ & $77(59.69)$ \\
$\geq 100 \mathrm{~mm} / \mathrm{hr}$ & $42(32.55)$ \\
Anemia & $177(84.69)$ \\
Mild anemia & $55(26.31)$ \\
Moderate anemia & $106(50.72)$ \\
Severe anemia & $16(7.66)$ \\
\hline
\end{tabular}

Among all patients who underwent sputum microscopy, 73 (34.93\%) patients had positive sputum smear for AFB. Data on sputum for Xpert MTB/RIF was available for 80 patients (14 positive for sputum AFB and 66 AFB negative patients), out which 48 (60\%) were positive. $14(100 \%)$ patients with AFB positive sputum and tested for Xpert MTB/RIF were positive for Xpert MTB/RIF. However, among 66 patients with sputum for AFB negative status, 34 (51.51\%) patients were positive for Xpert MTB/RIF (Table 3).

\begin{tabular}{|ll|}
\hline Table 3. Positive diagnostic test results. \\
\hline Variables & $\mathrm{n}(\%)$ \\
Sputum AFB $(\mathrm{n}=209)$ & $73(34.93)$ \\
Sputum Xpert MTB/RIF $(\mathrm{n}=80)$ & $48(60)$ \\
Lymph node for AFB $(\mathrm{n}=32)$ & $1(3.12)$ \\
Tissue Xpert MTB/RIF $\quad$ (cerebrospinal & $2(8.69)$ \\
fluid, lymphnode) $(\mathrm{n}=23)$ & \\
\hline
\end{tabular}

Among 153 patients of pulmonary tuberculosis, $73(47.71 \%)$ patients had sputum positive for AFB, $34(22.22 \%)$ patients were positive by Xpert MTB/ RIF and $14(9.15 \%)$ patients were positive for both AFB and Xpert MTB/RIF tests. In total, 107 (69.93\%) patients were bacteriologically confirmed pulmonary tuberculosis whereas $46(30.07 \%)$ were clinically diagnosed pulmonary tuberculosis.

Among 56 patients of extra pulmonary tuberculosis, only $3(5.35 \%)$ had tissue sample positive for either AFB or Xpert MTB/RIF and the remaining 53 $(94.65 \%)$ patients were clinically diagnosed with extra pulmonary tuberculosis.

\section{DISCUSSION}

Tuberculosis has high burden in Nepal. National tuberculosis prevalence survey 2018-19 has estimated the prevalence of tuberculosis to be $0.41 \%$ among 
the population. ${ }^{16}$ Three percent patients among all admissions in the medicine department in the present study were diagnosed with tuberculosis. Although relatively lower prevalence of tuberculosis is observed in hospital settings as a large proportion of patients are managed in outpatient basis, ${ }^{7}$ hospitalized patients imply more severe infections and/or presence of coinfections and thus requires special consideration for the diagnosis and management.

Tuberculosis can infect anyone irrespective of their age and sex but is common in young males, the commonest age group being 25-34 years and male to female ratio 1.7:1 reported previously. ${ }^{1,5}$ The older population commonly infected in the present study can largely be attributed to high risks of multiple co-morbidities and severe tuberculosis infection requiring hospital admission in older patients. ${ }^{11}$ Pulmonary tuberculosis is the commonest site of tuberculosis infection accounting for more than $80 \%$ of all tuberculosis, followed by lymphatic system as the commonest extrapulmonary site. ${ }^{5}$ Previous studies from Nepal comprising outpatients and inpatients have shown high prevalence of lymph node involvement, contributing to up-to $42 \%$ of all extra-pulmonary tuberculosis. ${ }^{16}$ Higher involvement of pleura $77 \%$ and central nervous system $11 \%$ in the present study conducted among inpatients could be due to the high severity with involvement of these sites needing hospitalization. This finding supports the previous finding of pleural involvement (55\% and $73 \%$ ) as the commonest extrapulmonary site among hospitalized patients. ${ }^{4,18}$

Diagnosis of tuberculosis remains a major challenge in the developing countries. ${ }^{19}$ In 2018, only around half of all reported pulmonary tuberculosis globally were bacteriologically confirmed. ${ }^{1}$ Although, data from high income settings with easy access to sensitive diagnostic tests like Xpert MTB/RIF have reported higher rates of bacterial confirmation, ${ }^{1}$ timely diagnosis lags behind in the developing countries. ${ }^{19}$ The conventional AFB microscopy has limited sensitivity in diagnosis ${ }^{9}$ and Xpert MTB/RIF is not readily available in resource-poor settings. ${ }^{20}$ Bacteriological confirmation limited to $70 \%$ of pulmonary tuberculosis and $5 \%$ of extrapulmonary tuberculosis in the present study with on-site facilities for microscopy and Xpert MTB/RIF points to the limited functional capacity of test facilities and underutilization of available tests in clinical diagnosis.

Only $5-10 \%$ of people infected with Mycobacterium tuberculosis develops tuberculosis disease but the risk is significantly higher among people with HIV co-infection, smoking and diabetes. ${ }^{5}$ HIV co-infection increases the risk for tuberculosis infection by 30 folds $^{5}$ and significantly increases the rate of progression of latent tuberculosis infection to disease. ${ }^{21}$ National Tuberculosis Program has emphasized for screening of HIV infection in all tuberculosis patients ${ }^{7}$ but the coverage of HIV testing in tuberculosis patients remain low in Nepal. HIV status was known in only around $40 \%$ patients in the present study with HIV prevalence of $1.43 \%$ among the population tested. This finding emphasizes on the need for strengthening HIV screening among all patients with tuberculosis.

Smoking has strong adverse effect on immune system of pulmonary tree and increases susceptibility to tuberculosis in a dose response manner. ${ }^{22,23}$ Smokers are twice as likely to be infected with tuberculosis and die from the disease. ${ }^{5}$ Similarly, Diabetes Mellitus also increases the risk of tuberculosis infection by two to three folds and has negative effect on treatment outcome. ${ }^{5,24}$ The high prevalence of smoking and diabetes in the present study supports the similar findings reported previously. ${ }^{24}$

Tuberculosis in most of the patients presents with clinical syndrome of respiratory symptoms like prolonged cough and hemoptysis, and non-specific constitutional symptoms like fever, loss of appetite and unintentional weight loss. ${ }^{13,25}$ The clinical presentation varies widely depending on the site of infection and other patient variables, but are often empirically used to make a diagnosis of tuberculosis in resource-poor settings with limited access to reliable tuberculosis diagnostics. A cautious approach to obtaining detailed clinical data combined with laboratory findings like blood counts ${ }^{26-28}$ and $\mathrm{ESR}^{5}$ in the absence of specific tuberculosis diagnostic can improve the diagnostic outcomes and guide monitoring of treatment response. Approaches to looking at relative neutrophil elevation compared to lymphocytes (neutrophillymphocyte ratio) is highly predictive of tuberculosis progression ${ }^{26-28}$ and should be routinely used in the monitoring of tuberculosis patients.

Given the retrospective nature of the analysis done on the secondary data of hospital records, there were limitations in the study. The possibility of missing data, especially the negative findings in the patient records could have influenced the results. However, attempts were made to review the complete patient records for pertinent data, and the findings from patients' history and laboratory records over the course of hospital admission were triangulated to retrieve the best available evidence.

\section{CONCLUSIONS}

Tuberculosis is a common cause of infections among hospital admitted patients in Nepal. Although a classic presentation of cough and fever are generally 
Thapa et al. Tuberculosis among Patients Admitted to the Department of Medicine of a Tertiary Care Center in Nepal: A Descriptive...

expected in tuberculosis, a large proportion of hospital admitted patients have extra pulmonary involvement which often present with atypical symptoms. Conventional AFB microscopy has limited sensitivity for the diagnosis of tuberculosis and improved access to reliable point-of-care diagnostic tests like Xpert MTB/RIF is urgently required. Findings from detailed history taking and hematological and biochemistry testing should be cautiously interpreted for timely identification and treatment of tuberculosis.

\section{ACKNOWLEDGEMENTS}

We would like to thank all the staff working in the record section of Patan hospital for their support in retrieving the data for the study.

Conflict of Interest: None.

\section{REFERENCES}

1. World Health Organization. Global Tuberculosis Report 2019. CC BY-NC-SA 3.0 IGO. Geneva: WHO, 2019. Available from: https://apps.who.int/iris/bitstream/handle/10665/ 329368/9789241565714-eng.pdf? sequence $=19 \&$ is Allowed $=y$ [Full text]

2. Kyu HH, Maddison ER, Henry NJ, Ledesma JR, Wiens KE, Reiner R, et al. Global, regional, and national burden of tuberculosis, 1990-2016: results from the Global Burden of Diseases, Injuries, and Risk Factors 2016 Study. The Lancet Infectious Diseases 2018;18(12):1329-49. [ | DOI]

3. Nguyen L. Antibiotic resistance mechanisms in $\mathrm{M}$. tuberculosis: an update. Archives of Toxicology 2016;90(7):1585-604. [uuㄹed | Full text | DOI]

4. B. Bilagi R, Deshmukh H. Study of clinical profile of tuberculosis patients admitted in respiratory medicine ward at a tertiary care hospital in Marathwada. International Journal of Advances in Medicine 2018;5(1):68. [Full text | DOI]

5. Rohini K, Surekha Bhat M, Srikumar PS, Mahesh Kumar A. Assessment of Hematological Parameters in Pulmonary Tuberculosis Patients. Indian Journal of Clinical Biochemistry 2016;31(3):332-5. [PubMed | Full text | DOI]

6. Oni T, Berkowitz N, Kubjane M, Goliath R, Levitt Naomi S, Wilkinson RJ. Trilateral overlap of tuberculosis, diabetes and HIV-1 in a high-burden African setting: implications for TB control. European Respiratory Journal 2017;50(1):1-10. [ $\underline{\text { PubMed }}|\underline{\text { Full text }}| \underline{\text { DOI] }}$

7. Ministry of Health and Population of Nepal. National Tuberculosis Management Guidelines. Thimi, Bhaktapur National Tuberculosis Center, 2019. Available from: https://nepalntp.gov.np/wp-content/uploads/2019/10/ National-Tuberculosis-Management-Guidelines-2019_ Nepal.pdf. [Full text]

8. Kulchavenya E. Extrapulmonary tuberculosis: are statistical reports accurate? Therapeutic Advances in Infectious Disease 2014;2(2):61-70. [PubMed | Full text | DOI]

9. Singhal R, Myneedu VP. Microscopy as a diagnostic tool in pulmonary tuberculosis. International Journal of Mycobacteriology 2015;4(1):1-6. [uㅏbMed | Full text | DOI]

10. Verma S, Dhungana G, Joshi H, Kunwar H, Pokhrel A. Prevalence of pulmonary tuberculosis among HIV infected persons in Pokhara, Nepal. Journal of Nepal Health Research Council 2012;10:32-6. [PubMed | Full text | DOI]
11. Ronald LA, FitzGerald JM, Benedetti A, Boivin J-F, Schwartzman K, Bartlett-Esquilant G, et al. Predictors of hospitalization of tuberculosis patients in Montreal, Canada: a retrospective cohort study. BMC Infectious Diseases 2016;16(1):679. [uuMed | Full text | DOI]

12. Center for Disease Control and Prevention. Adult Tobacco Use Information. 2017 August 29. Available from: https:// www.cdc.gov/nchs/nhis/tobacco/tobacco_glossary.htm. [Full text]

13. American Diabetes Association. Classification and Diagnosis of Diabetes: Standards of Medical Care in Diabetes - 2020 . Diabetes Care 2020;43:S14-S31. [uued | Full text | DOI]

14. Firdaus S PB, Ramadevi M, Reddy TM, Jayabhaskar C. A Study of Hematological Abnormalities in Patients With Tuberculosis. IOSR Journal of Dental and Medical Sciences (IOSR-JDMS) 2020;19(2):3. [ Full text | DOI]

15. World Health Organization. International Statistical Classification of Diseases and Related Health Problems (ICD). 2018. Available from: https://www.who.int/ classifications/classification-of-diseases. [Full text]

16. Government of Nepal Ministry of Heath and Population National TB Control Centre. NEPAL NATIONAL TB PREVALENCE SURVEY BRIEF. 2020. Available from: https://www.who.int/docs/default-source/ nepal-documents/policy-brief.pdf?sfvrsn=37b5881c_2. [Full text]

17. Sreeramareddy CT, Panduru KV, Verma SC, Joshi HS, Bates MN. Comparison of pulmonary and extrapulmonary tuberculosis in Nepal- a hospital-based retrospective study. BMC Infectious Diseases 2008;8(1):8. [PubMed | Full text | DOI]

18. Gaur PS, Suryakant, Bhaskar R, Singh $S$, Saxena $P$, Agnihotri S. Incidence and Clinical profiles of Pulmonary and Extra-Pulmonary Tuberculosis patients in North Indian population: A hospital based Retrospective study. International Journal of Research and Development in Pharmacy \&amp; Life Sciences 2017;6(5):2773 - 8. [Full text | DOI]

19. Harries AD, Kumar AMV. Challenges and Progress with Diagnosing Pulmonary Tuberculosis in Low- and Middle-Income Countries. Diagnostics 2018;8(4):78. [PubMed | Full text | DOI]

20. Albert $H$, Nathavitharana RR, Isaacs $C$, Pai $M$, Denkinger CM, Boehme CC. Development, roll-out and impact of Xpert MTB/RIF for tuberculosis: what lessons have we learnt 
Thapa et al. Tuberculosis among Patients Admitted to the Department of Medicine of a Tertiary Care Center in Nepal: A Descriptive...

and how can we do better? European Respiratory Journal 2016;48(2):516. [PubMed | Full text | DOI]

21. Esmail H, Riou C, du Bruyn E, Lai RP-J, Harley YXR, Meintjes $G$, et al. The Immune Response to Mycobacterium tuberculosis in HIV-1-Coinfected Persons. Annual Review of Immunology 2018;36(1):603-38. [uuMed | Full text | DOI]

22. Feng $\mathrm{Y}$, Kong $\mathrm{Y}$, Barnes PF, Huang FF, Klucar P, Wang X, et al. Exposure to cigarette smoke inhibits the pulmonary T-cell response to influenza virus and Mycobacterium tuberculosis. Infection and immunity 2011;79(1):229-37. [PubMed | Full text $\mid \underline{\mathrm{DOI}}]$

23. Zhang H, Xin H, Li X, Li H, Li M, Lu W, et al. A dose-response relationship of smoking with tuberculosis infection: A cross-sectional study among 21008 rural residents in China. PloS one 2017;12(4):e0175183. [uㅏbMed | Full text | DOI]

24. Jiyani M. R VPK, Pandey A. S, Modh D. A. Clinical Profile and outcome of Tuberculosis in Patients with Diabetes. Internal Journal of Research in Medicine 2015;4(2):36-40. [Full text]

25. Shah BK, Mishra SK. Clinico-laboratory Profile of Childhood Tuberculosis Admitted at a Tertiary Hospital in Nepal.
Journal of Advances in Medicine and Medical Research 2018;28(1):1-6. [Full text | DOI]

26. Miyahara R, Piyaworawong S, Naranbhai V, Prachamat $\mathrm{P}$, Kriengwatanapong P, Tsuchiya N, et al. Predicting the risk of pulmonary tuberculosis based on the neutrophil-tolymphocyte ratio at TB screening in HIV-infected individuals. BMC Infectious Diseases 2019;19(1):667. [PubMed | Full text [ DOI]

27. Jeon Y, Lee WI, Kang SY, Kim MH. Neutrophil-to-Monocyte-Plus-Lymphocyte Ratio as a Potential Marker for Discriminating Pulmonary Tuberculosis from Nontuberculosis Infectious Lung Diseases. Laboratory medicine 2019;50(3):286-91. [PubMed | Full text | DOI]

28. Yoon N-B, Son C, Um S-J. Role of the neutrophil-lymphocyte count ratio in the differential diagnosis between pulmonary tuberculosis and bacterial community-acquired pneumonia. Annals of Laboratory Medicine 2013;33(2):105-10. [PubMed I Full Text]

This work is licensed under a Creative Commons Attribution 4.0 International License. The images or other third party material in this article are included in the article's Creative Commons license, unless indicated otherwise in the credit line; if the material is not included under the Creative Commons license, users will need to obtain permission from the license holder to reproduce the material. To view a copy of this license, visit http://creativecommons.org/licenses/by/4.0/ 